\title{
Effect of Health Education Program on Improving Health Awareness Teachers Knowledge and Practice toward Adolescent Reproductive Health at Al-jouf City
}

\author{
Nahed E. El-sabagh ${ }^{1}$, Samar S. Diab ${ }^{2}$, Nevein M. Hasanein ${ }^{3}$, Shifa H. Alqsiri ${ }^{4}$ \\ ${ }^{I}$ Obstetric and Gynecology Nursing, College of Applied Medical Sciences, Aljouf University, Saudi Arabia \\ ${ }^{2}$ Pediatric Nursing, College of Applied Medical Sciences, Aljouf University, Saudi Arabia \\ ${ }^{3}$ Maternity and Child Health Nursing, College of Applied Medical Sciences, Aljouf University, Saudi Arabia \\ ${ }^{4}$ Community Health Nursing, College of Applied Medical Sciences, Aljouf University, Saudi Arabia
}

\begin{abstract}
:
Background: Adolescents' Reproductive health (ARH) is an integrated approach to the health and development needs of adolescens. The reproductive health needs of adolescents have been mostly overlooked todate by existing reproductive health services and information. Health awareness teacher or school nurse has an important role in the provision of school health services.

Aim of this Study: was to evaluate the effectiveness of health education program on health awareness teachers' knowledge and practice toward adolescent's reproductive health.

Design: quasi-experimental study was used in this study. The study was conducted atAljouf University, Girls Colleges- Faculty of Applied Medical Science through sessions in a study room.

Sample: all the available health awareness teachers who are working in the governmental and private girls schools in Al-jouf city were included in this study. The total number was 54 health awareness teachers

Tools:(1) Questionnaire sheet was used to collect demographic data about the study subjects and their knowledge about (ARH) (2) Observational checklist was developed to assess their practice of breast selfexamination (BSE) and (3) Health educational program using a booklet including teaching about (ARH) was developed based on the health awareness teachers' needs. The effectiveness of the health educational program was evaluated by comparing the scores of the health awareness teachers' knowledge and practice regarding (ARH) before, immediately and 3 months after the health educational program.

Results: The findings of the study revealed that the health awareness teachers' knowledge improved Regarding (ARH). Those who have good knowledge regarding ARH were improved significantly from 38.9\% pre-program to $100 \%$ immediate post-program and 100\% 3 months post-program. Regarding the breast self-examination (BSE), none of the study sample had a good practice before intervention while all became good practice immediately after intervention and reduced to $31.5 \%$ after 3 months post program. It can be concluded that educational program has a positive effect on the health awareness teachers' knowledge and practice regarding (ARH).The study recommended raising the awareness of health awareness teachers about (ARH) through the periodic health education programs that help them to offer high quality of care to adolescents in a nonjudgmental confidential manner.
\end{abstract}

Keywords: adolescents' reproductive health, knowledge and practice, breast self-examination, Health awareness teacher or school nurse.

\section{Introduction}

Adolescence is a journey from the childhood to the world of an adult, a time of physical, psychological and emotional changes1. The definition of this period differs from one country to another. World Health Organization (WHO) defines adolescents as young people aged 10-19 years. Eighty-eight percent of the world's 1.2 billion adolescents live in developing countries with a considerable number living in the Arab world ${ }^{2}$.The Kingdom of Saudi Arabia (KSA) has a population exceeding 27 million, and $20 \%$ of its population is adolescent aged 10- 19 years ${ }^{3}$. National data sets on adolescent are lacking and there is a shortage of adolescenthealth services and programs ${ }^{4}$. Furthermore, the research carried out in the region has generally excluded important aspects of adolescent health including alcohol/substance use andsexual/reproductive health ${ }^{5}$ because of cultural sensitivities and taboos associated with such.

Reproductive Health Overview (RHO) mentioned that although adolescence generally is a healthy period of life, many adolescents often are less informed, less experienced, and less comfortable accessing reproductive health services than adults ${ }^{6}$. WHO (2009) agreed on an internationally recognized definition of reproductive healthas a state of complete physical, mental and social wellbeing and not merely absence of disease orinfirmity in all matters relating to the reproductive system and to its functions and process at all stages 
of life ${ }^{(7)}$. Adolescents' reproductive health is an integrated approach to the health and development needs of adolescents. The reproductive health needs of adolescents as a group have been largely ignored to-date by existing reproductive health services and information ${ }^{6}$.

Teaching adolescents about the problems they meet will help them to mature in a healthy way. Adolescents' lack of existing general knowledge and information about reproductive health, as well as a lack of agreement on and provision of adequate counseling and educational services appropriate for them, have hindered potential progress ${ }^{(6,7)}$. Lack of availability of general information about reproductive health: To-date, information and education on adolescent's reproductive health specifically targeting Saudi young adults have been severely limited. This topic is been "covered only minimally in the school curriculum and the media, and often not addressed within families and health providers ${ }^{4,8}$.

Schools have uniquely high access to youth; they are extremely well-suited places in which to prevent reproductive health problems. School programs should be tailored to meet the needs of adolescents. Programs must be supported by administrators and other school staff. School nurses and health awareness teachers are having multiple roles in counseling, educating, and providing care. School staff must be knowledgeable about adolescent's reproductive health and comfortable discussing it. Further, staff also needs to be well-informed about and respect students' rights to privacy ${ }^{9,}{ }^{10}$ School nurse and health awareness teacher have crucial role in provision of comprehensive health services to children and youth, and consider as important team member in providing preventive services, early identification of problems, interventions, and referrals to foster health and educational success ${ }^{10,11}$.

A study conducted at Alexandria Egypt ${ }^{(12)}$ assessing knowledge of adolescents regarding reproductive health, found lack of knowledge regarding reproductive health among their study sample. It also recommended educating school nurses in order to be adequately prepared to teach the adolescents about reproductive health aspects. Another study conducted by Gaheen et al recommended that raising the awareness of school nurses regarding adolescent's reproductive health through the periodic health education programsthat help them to offer high quality of care to adolescents in a non-judgmental confidential manner and to know where to refer adolescents for more information and health services ${ }^{13}$.

School nurse and heath awareness teacher has a central role in the implementation of the school health services program for all adolescents in the school, so it is important to design a program for health awareness teachers to provide them by knowledge and practice related to the adolescent's reproductive health, including physiological and psychological development during adolescence, anatomy of female reproductive system, common menstrual problems, breast self-examination, premarital counseling, sexually transmitted diseases, nutritional problems and needs among adolescents, smoking and addiction among adolescents and the health awareness teacher role in promoting adolescent's reproductive health ${ }^{10,11}$.

No research had been conducted on adolescent's reproductive health knowledge and practice among health awareness teachers in Kingdom of Saudi Arabia in general and in Aljouf city in specific. So, the present study will be conducted to examining this void in our knowledge in an effort to learn more about the effect of health education program on improving health awareness teachers' knowledge and practice toward adolescent's reproductive health.

The aim of the study: To evaluate the effectiveness of health education program on health awareness teachers' knowledge and practice toward adolescent's reproductive health at Aljouf city

\section{Hypothesis of the study}

1- Health education program has a positive effect on the health awareness teachers' knowledge and practice regarding adolescent's reproductive health.

2- The level of health awareness teachers' knowledge and practice regarding adolescent's reproductive health will be effected by their socio-demographic characteristics.

\section{Subjects and Method}

Study design: Interventional quasi- experimental design, none-equivalent control group design: one group pretest, immediate post-test and follow-up test design was used to conduct this study. In this design the pretest scores serve the same function as a control group. A quasi- experimental design does not need to have random assignment.

Setting of the study: The study was conducted at Aljouf University, Girls Colleges- Faculty of Applied Medical Science through sessions in a study room.

Sample:All the available health awareness teachers who are working in the governmental and private intermediate girls schools in Al-Jouf city (Sakaka, Domaa and Tapargal), different ages and qualifications was asked to be included in this study. The total number of 54 health awareness teachers was included in this study. 


\section{Tools of data collection}

Three tools were used by the researchers for data collection:

Tool I: Questionnaire sheet: A questionnaire sheet was developed by the researchers to collect the necessary data about the study subjects. This sheet included two main parts:

The first part: Was intended to obtain information about health awareness teachers' socio-demographic characteristics such as [age, marital status, level of education, years of experience, place of residence].

The second part:These included nine sections which consisted of set of questions to assess health awareness teachers' knowledge regarding:

1- The concept of reproductive health and its important, different stages of adolescents, common adolescent's reproductive health problems, Role and source of health awareness teacher's information.

2- Anatomy of the internal and external organs of female reproductive system, definition of hymen, physical changes associated with puberty and its effect on adolescent's behavior.

3- Menstruation(duration, interval, and amount), signs and symptoms associated with menstruation and menstrual hygiene.

4- Importance of breast self-examination, proper time to perform breast self-examination, steps of breast selfexamination.

5- The importance of premarital counseling and its services, common places to attain premarital services.

6- Common types of sexual transmitted diseases(STDs), definition, signs and symptoms and methods of transmission of each.

7- Adolescent's nutrition and complication of imbalanced diet.

8- Smoking and addiction during adolescence period: types of smoking and its side effect on health, physical and psychological effect of addiction and its effect on behavior.

\section{Scoring system of tool I part 2:-}

The distribution and percentage of correct answers of each question were computed.

- Questions which assess the knowledge, the answer of each question was scored as the following:

a- The answers by Yes or No in questionnaire sheet: each question was given two marks if the answer was Yes, one mark if the answer was No.

b- Right, Wrong or don't know answers: each question was given two marks if the answer was right and one marks if the answer was wrong.

c- Complete, Incomplete and Wrong answers: each question was given three marks if the answer was complete, two marks if the answer was Incomplete and one mark if the answer was wrong.

- If all: $2 / 3$ of answers were chosen, it is considered as complete answer.

- If $1 / 3$ to less than $2 / 3$ answers were chosen, it is considered as incomplete answer.

- $\quad$ If 0 to less than $1 / 3$ answers were chosen. It is considered as wrong answer.

The possible range of scores was zero to 111.

- Health awareness teachers 'total knowledge scores were classified as follows:

Goodknowledge

Moderate knowledge

Poorknowledge
(75\% or more correct answers)

(50\%-74\% correct answers)

(less than $50 \%$ correct answers)

Tool II: Observational Checklist for breast self-examination was developed by the researchers to assess health awareness teachers 'practice regarding breast self-examination before, immediately after the sessions, and 3 months after sessions. This sheet included the examination in front the mirror, on lying position, during taking bath.

Scoring system of tool II:-Each step of examination was given two marks if done perfectly, one mark if done not perfectly and zero if not done. The total score of practice ranged from $0-16$, it was categorized into 3 groups: Good: Score ranged from 10-16 marks.

Moderate: Score ranged from 5 - <10 marks.

Poor: Score ranged from $0-<5$ marks.

Tool III:Booklet was developed by the researchers including all information needed for health awareness teachers about adolescent's reproductive health which included in tool I part 2 and the steps of breast selfexamination technique, using simple Arabic language and illustrated pictures. 


\section{Ethical consideration:}

- Before conducting the study, all the health awareness teachers who participated were informed orally by the purpose of the study and right to withdraw from the study at any time if desired. There are no known physical or psychological risks associated with participating in this study.

- Oral consent from all subjects in this study was taken. The study tools have only code number without using subject's name. All data were kept in a locked file cabinet.

\section{Operational design}

A- Preparatory phase: A review of the current and past relevant literature was done to plan for the contents of educational program for health awareness teachers regarding adolescent's reproductive health and develop the study tools. Content validity of the tools was established by juryof professors of obstetric nurses and physicians.

B- Pilot study: After the development of tools, a pilot study was conducted on a sample of five health awareness teachers. The aim of this pilot study was to assess the clarity, relevance and time needed for completion of the tools. Furthermore, detect any problems in data collection and make any modification needed. These health awareness teachers were not excluded from the study sample due to limited number of them and no addition or omission was required after pilot study implementation.

C- The study was conducted in the period ranging from 5/2015 to 9/2015 (4 months).

\section{Assessment Phase}

Three assessments were conducted to the health awareness teachers to test their knowledge about adolescent's reproductive health and performance of breast self-examination (using tool I part (2) and tool II).

- First time assessment: Tools were used to get a base--line assessment for health awareness teachers prior to the development of the program.

- Second time assessment: Immediately after the implementation of the educational program to compare between the results (pre-and Immediate post-tests) to determine the level of improvement.

- Third time: 3 months after the implementation of the educational intervention to assess the retained knowledge and practice by follow-up test using the same format tools of pre-test and immediate post-test.

- Various teaching methods were selected and utilized, which included the following:

a- Lectures followed by open discussions, b- Demonstration and re-demonstration:

c- Instructional materials Such as handout, data show, using simulators, role playing, and a guide booklet.

\section{Implementation of the Program:}

The intervention included 8 sessions and carried-out in the previous mentioned setting, the duration of each session was 1 hour including the period of open discussion except the fourth session of re-demonstration of breast self- examination techniques (it took 2 hours). The content of the sessions was presented for 4 consecutive days, two sessions was given per day.

\section{Day One:-}

1- The researcher explained the purpose of the study to the health awareness teachers to obtain their approval. Before starting the sessions, the researcher used (tool I part 1and 2) to collect the socio-demographic characteristics for all health awareness teachers at the same time and to assess health awareness teachers' knowledge of adolescent's reproductive health. The tool I took 20-30 minutes to be completed, followed by using the breast-self-examination observational checklist (tool II) to assess and observe the performance of each health awareness teachers. It took 5 minutes to be completed.

2- The researcher distributed the booklet at the beginning of the first session.

- The first session was given from 10 A.M to 11 A.M. The researcher explained the concept of reproductive health and its importance, different stages of adolescence, common adolescent's health problems, followed by break time.

- Then the second session was given from 12.30 B.M to1.30 P.M to explain the anatomy of the internal and external organs of the female reproductive system, definition of hymen, menstruation, signs and symptoms associated with menstruation, menstrual hygiene, physical changes associated with puberty and its effect on adolescent's behavior .

Day two:-

- The third session was given from 9.00 A.M to 10 A.M, the researcher explain the importance of breast selfexamination, proper time and demonstrate the steps of breast self-examination techniques followed by break time. 
- The fourth session was given from 10.30 A.M to12.30 A.M, for re-demonstration the steps of breast selfexamination techniques by health awareness teachers where they divided into 4 groups, each group consisted of 10health awareness teachers to ease assessment and observation by the researchers, then discussed the importance of premarital counseling, its services and most common places to attain premarital services.

\section{Day three: -}

- The fifth session was given from 9.00 A.M to 10 A. M., to explain the types of sexual transmitted diseases (STDs), signs and symptoms of STDs, AIDS, signs and symptoms of AIDS, methods of transmission of AIDS, followed by break time.

- Then the sixth session was given from 10.30 A.M to11.30 A.M, to explain the importance of proper nutrition during adolescents, common mistakes done by adolescents regarding their nutrition, complication of poor balanced diet, component of good balanced diet followed by break time

\section{Day four: -}

- The seventh session was given from 9.00 A.M to 10 A.M, to discuss the types of smoking, side effect and complication of smoking followed by break time.

- Then the eighth session was given from 10.30 A.M to11.30 A.M, to discuss the signs and symptoms of addiction, the physical, psychological and behavior effect of addiction and the role of health awareness teachers.

- Post-test was conducted using (Tool I part 2 and tool II) to assess and observe school nurses knowledge and performance (immediately after nursing intervention) and evaluate the effectiveness of the program.

\section{Administrative Design}

Before starting the study, Bioethics Committee approval- Aljouf University was taken, and an official letter from the Dean of faculty of Applied Medical Sciences- AljoufUniversity was forwarded to Director General of education to get the approval for data collection and implementation of educational sessions. The purpose of the study and duration of its fulfillment was explained.

\section{Statistical Analysis}

After data were collected it was revised, coded and fed to statistical softwareSPSSIBM version 20. All statistical analysis was done using two tailed tests and alpha error of 0.05 . All discrete scores for items concerning knowledge or breast self-examination were summed together and average score were calculated. Descriptive statistics in the form of frequencies and percent were used to describe the categorical data variables while scale data were expressed by mean and standard deviation. To test for differences at each scale item frequencies between different study phases, Friedman test for repeated categorical measures was used while repeated measures ANOVA was used to compare mean scores. For testing for relation between knowledge level or BSE categories and different sample demographic characteristics, Fisher exact using Mont Carlo method was used.

\section{Limitation of the study}

- The total hours of the educational program was 9 hours instead of 8 hours (one hour added to the fourth session).

- At the time of 3 months evaluation of health awareness teacherssome of them did not come because they were busy. In order to overcome these problems, the researcher visited the health awareness teachers at their schools to fill the 3 months post- test questionnaire and evaluate their practice regarding breast selfexamination.

\section{Results}

Table1: Socio-demographic characteristics of the study subjects

\begin{tabular}{|c|l|l|}
\hline Demographic data & No & \% \\
\hline Age in years & & \\
\hline - 25- <35 & 20 & $37.0 \%$ \\
\hline - $45-<45$ & 31 & $57.4 \%$ \\
\hline Mean \pm SD & 3 & $5.6 \%$ \\
\hline Marital status & \multicolumn{2}{|l|}{$34.9 \pm 5.7$} \\
\hline - married & \multicolumn{2}{|l|}{} \\
\hline - single & 39 & $72.2 \%$ \\
\hline - Divorced & 8 & $14.8 \%$ \\
\hline Educational Level & 7 & $13.0 \%$ \\
\hline B Bachelor degree & & \\
\hline
\end{tabular}




\begin{tabular}{|c|l|l|}
\hline - postgraduate studies (Diploma) & 5 & $9.3 \%$ \\
\hline Experience in years & \multicolumn{2}{|l|}{} \\
\hline - $<3$ years & 28 & $51.9 \%$ \\
\hline - 3+ & 26 & $48.1 \%$ \\
\hline Mean \pm SD & $2.4 \pm 0.9$ \\
\hline Adolescents in family & \multicolumn{2}{|l|}{} \\
\hline - One & 8 & $24.2 \%$ \\
\hline - 2-3 & 20 & $60.6 \%$ \\
\hline - 4+ & 5 & $15.2 \%$ \\
\hline Mean \pm SD & $2.4 \pm 1.2$ \\
\hline Type of residence & \multicolumn{2}{|l}{} \\
\hline - Rural & 11 & $20.4 \%$ \\
\hline - Urban & 43 & $79.6 \%$ \\
\hline
\end{tabular}

The sample consisted of 54 health awareness teachers. The socio-demographic characteristics of the subjects are presented in table 1 . Subjects ranged in ages from 25 to 53 years. The mean age was $34.9 \pm 5.7$. The majority of the study subjects were married (72.2\%) and most of them had a college degree $(90.7 \%)$. Over onehalf of the subjects $(51.9 \%)$ their years of experience were less than 3 years with a mean $2.4 \pm 0.9$. It was also noticed that over two-third of the subjects $(60.6 \%)$ have adolescents in their family with a mean $2.4 \pm 1.2$. The majority of the sample (79.6\%) was from urban areas.

Table 2: Knowledge score of the health awareness teachers regarding adolescents' reproductive health preprogram, immediate post-program and 3 months post-program.

\begin{tabular}{|c|c|c|c|c|c|c|c|c|}
\hline \multirow[t]{3}{*}{ Knowledge items } & \multicolumn{6}{|l|}{ Phase } & \multirow[t]{3}{*}{$\mathbf{P}$} & \multirow{3}{*}{$\begin{array}{l}\square \text { - } \\
\text { Cronbach's }\end{array}$} \\
\hline & \multicolumn{2}{|l|}{ Pre } & \multicolumn{2}{|c|}{ Immediate Post } & \multicolumn{2}{|c|}{3 months post } & & \\
\hline & Mean & SD & Mean & SD & Mean & SD & & \\
\hline $\begin{array}{l}\text { Knowledge about reproductive health and } \\
\text { adolescent }\end{array}$ & 9.74 & 1.70 & 12.78 & .69 & 12.09 & 1.07 & $0.001 *$ & 0.857 \\
\hline $\begin{array}{l}\text { knowledge about anatomy and physical } \\
\text { and behavioral changes }\end{array}$ & 10.19 & 1.20 & 13.65 & .73 & 12.72 & 1.43 & $0.001^{*}$ & 0.778 \\
\hline $\begin{array}{l}\text { knowledge about menstruation and } \\
\text { menstrual hygiene }\end{array}$ & 17.00 & 2.93 & 22.96 & 1.39 & 22.13 & 2.13 & $0.001 *$ & 0.964 \\
\hline knowledge about breast self examination & 6.70 & 2.28 & 11.00 & 0.00 & 10.52 & .75 & $0.001 *$ & 0.759 \\
\hline knowledge about premarital counseling & 5.52 & 4.13 & 10.81 & .62 & 10.33 & 1.20 & $0.001^{*}$ & 0.715 \\
\hline knowledge of sexual transmitted diseases & 8.83 & 2.49 & 12.76 & .51 & 11.94 & 1.22 & $0.001 *$ & 0.773 \\
\hline knowledge about diet & 7.22 & 1.64 & 8.96 & .19 & 8.50 & 1.02 & $0.001^{*}$ & 0.806 \\
\hline knowledge about smoking and addiction & 6.78 & 2.65 & 10.81 & .39 & 10.11 & 1.19 & $0.001 *$ & 0.736 \\
\hline $\begin{array}{l}\text { knowledge about role of health awareness } \\
\text { teachers in relation to reproductive health }\end{array}$ & 3.65 & 1.01 & 4.81 & .39 & 4.70 & .46 & $0.001 *$ & 0.701 \\
\hline Overall knowledge & 75.63 & 13.37 & 108.56 & 2.31 & 103.06 & 5.15 & $0.001^{*}$ & 0.834 \\
\hline
\end{tabular}

P: repeated measures ANOVA

$* \mathrm{P}<0.05$ (significant)

Table 2: demonstrates the change at knowledge score during different phases of the study. It is obvious that knowledge about reproductive health and adolescent was significantly improved from 9.7 before intervention to 12.7 and 12.1 after intervention (immediately post and 3 month post) with statistically significant trend $(\mathrm{P}<0.001)$. As regard knowledge about anatomy and physical and behavioral changes, was significantly improved from 10.2 before intervention to 13.7 and 12.7 after intervention (immediately post and 3 month post) with statistically significant trend $(\mathrm{P}<0.001)$. Concerning knowledge about menstruation and menstrual hygiene, was significantly improved from 17.0 before intervention to 23.0 and 22.1 after intervention (immediately post and 3 month post) with statistically significant trend $(\mathrm{P}<0.001)$. For knowledge about breast self- examination, was significantly improved from 6.7 before intervention to 11.0 and 10.5 after intervention (immediately post and 3 month post) with statistically significant trend $(\mathrm{P}<0.001)$. Regarding knowledge about premarital counseling, was significantly improved from 5.5 before intervention to 10.8 and 10.3 after intervention (immediately post and 3 month post) with statistically significant trend $(\mathrm{P}<0.001)$. As regard knowledge of sexual transmitted diseases, was significantly improved from 8.8 before intervention to 12.8 and 12.0 after intervention (immediately post and 3 month post) with statistically significant trend $(\mathrm{P}<0.001)$. Concerning knowledge about diet, was significantly improved from 7.2 before intervention to 9.0 and 8.5 after intervention (immediately post and 3 month post) with statistically significant trend $(\mathrm{P}<0.001)$. Concerning knowledge about smoking and addiction, was significantly improved from 6.8 before intervention to 10.8 and 10.1 after intervention (immediately post and 3 month post) with statistically significant trend $(\mathrm{P}<0.001)$. Regarding knowledge about role of health awareness teachers in relation to reproductive health, was significantly improved from 3.7 before intervention to 4.8 and 4.7 after intervention (immediately post and 3 month post) with statistically significant trend $(\mathrm{P}<0.001)$. 
Table 3: Level of knowledge of health awareness teachers regarding adolescents 'reproductive health during pre-program immediate post- program and 3 months post program.

\begin{tabular}{|c|c|c|c|c|c|c|c|c|}
\hline \multirow[t]{3}{*}{ Knowledge } & & \multicolumn{6}{|c|}{ Phase } & \multirow[t]{3}{*}{$\mathbf{P}$} \\
\hline & & \multicolumn{2}{|c|}{ Pre } & \multicolumn{2}{|c|}{ Immediate Post } & \multicolumn{2}{|c|}{3 months post } & \\
\hline & & No & $\%$ & No & $\%$ & No & $\%$ & \\
\hline \multirow{3}{*}{$\begin{array}{l}\text { Knowledge about reproductive } \\
\text { health and adolescent }\end{array}$} & Poor & 3 & $5.6 \%$ & 0 & $0.0 \%$ & 0 & $0.0 \%$ & \multirow[t]{3}{*}{$0.001 *$} \\
\hline & Moderate & 18 & $33.3 \%$ & 0 & $0.0 \%$ & 0 & $0.0 \%$ & \\
\hline & Good & 33 & $61.1 \%$ & 54 & $100.0 \%$ & 54 & $100.0 \%$ & \\
\hline \multirow{3}{*}{$\begin{array}{l}\text { knowledge about anatomy and } \\
\text { physical and behavioral changes }\end{array}$} & Poor & 1 & $1.9 \%$ & 0 & $0.0 \%$ & 0 & $0.0 \%$ & \multirow[t]{3}{*}{$0.001^{*}$} \\
\hline & Moderate & 27 & $50.0 \%$ & 0 & $0.0 \%$ & 4 & $7.4 \%$ & \\
\hline & Good & 26 & $48.1 \%$ & 54 & $100.0 \%$ & 50 & $92.6 \%$ & \\
\hline \multirow{3}{*}{$\begin{array}{l}\text { knowledge about menstruation } \\
\text { and menstrual hygiene }\end{array}$} & Poor & 2 & $3.7 \%$ & 0 & $0.0 \%$ & 0 & $0.0 \%$ & \multirow[t]{3}{*}{$0.001 *$} \\
\hline & Moderate & 30 & $55.6 \%$ & 0 & $0.0 \%$ & 2 & $3.7 \%$ & \\
\hline & Good & 22 & $40.7 \%$ & 54 & $100.0 \%$ & 52 & $96.3 \%$ & \\
\hline \multirow{3}{*}{$\begin{array}{l}\text { knowledge about } \text { breast } \\
\text { examination }\end{array}$} & Poor & 12 & $22.2 \%$ & 0 & $0.0 \%$ & 0 & $0.0 \%$ & \multirow[t]{3}{*}{$0.001 *$} \\
\hline & Moderate & 30 & $55.6 \%$ & 0 & $0.0 \%$ & 0 & $0.0 \%$ & \\
\hline & Good & 12 & $22.2 \%$ & 54 & $100.0 \%$ & 54 & $100.0 \%$ & \\
\hline \multirow{3}{*}{$\begin{array}{lll}\text { knowledge } & \text { about } & \text { premarital } \\
\text { counseling } & & \end{array}$} & Poor & 25 & $46.3 \%$ & 0 & $0.0 \%$ & 0 & $0.0 \%$ & \multirow[t]{3}{*}{$0.001 *$} \\
\hline & Moderate & 10 & $18.5 \%$ & 2 & $3.7 \%$ & 10 & $18.5 \%$ & \\
\hline & Good & 19 & $35.2 \%$ & 52 & $96.3 \%$ & 44 & $81.5 \%$ & \\
\hline \multirow{3}{*}{$\begin{array}{l}\text { knowledge o sexual transmitted } \\
\text { diseases }\end{array}$} & Poor & 6 & $11.1 \%$ & 0 & $0.0 \%$ & 0 & $0.0 \%$ & \multirow[t]{3}{*}{$0.001 *$} \\
\hline & Moderate & 24 & $44.4 \%$ & 0 & $0.0 \%$ & 0 & $0.0 \%$ & \\
\hline & Good & 24 & $44.4 \%$ & 54 & $100.0 \%$ & 54 & $100.0 \%$ & \\
\hline \multirow[t]{3}{*}{ knowledge about diet } & Poor & 2 & $3.7 \%$ & 0 & $0.0 \%$ & 0 & $0.0 \%$ & \multirow[t]{3}{*}{$0.001 *$} \\
\hline & Moderate & 7 & $13.0 \%$ & 0 & $0.0 \%$ & 6 & $11.1 \%$ & \\
\hline & Good & 45 & $83.3 \%$ & 54 & $100.0 \%$ & 48 & $88.9 \%$ & \\
\hline \multirow{3}{*}{$\begin{array}{l}\text { knowledge about smoking and } \\
\text { addiction }\end{array}$} & Poor & 10 & $18.5 \%$ & 0 & $0.0 \%$ & 0 & $0.0 \%$ & \multirow[t]{3}{*}{$0.001 *$} \\
\hline & Moderate & 32 & $59.3 \%$ & 0 & $0.0 \%$ & 9 & $16.7 \%$ & \\
\hline & Good & 12 & $22.2 \%$ & 54 & $100.0 \%$ & 45 & $83.3 \%$ & \\
\hline \multirow{3}{*}{$\begin{array}{l}\text { knowledge aboutrole of health } \\
\text { awareness teachers in relation to } \\
\text { adolescent reproductive health }\end{array}$} & Poor & 6 & $11.1 \%$ & 0 & $0.0 \%$ & 0 & $0.0 \%$ & \multirow[t]{3}{*}{$0.001 *$} \\
\hline & Moderate & 10 & $18.5 \%$ & 0 & $0.0 \%$ & 0 & $0.0 \%$ & \\
\hline & Good & 38 & $70.4 \%$ & 54 & $100.0 \%$ & 54 & $100.0 \%$ & \\
\hline \multirow[t]{3}{*}{ Overall knowledge } & Poor & 6 & $11.1 \%$ & 0 & $0.0 \%$ & 0 & $0.0 \%$ & \multirow[t]{3}{*}{$0.001^{*}$} \\
\hline & Moderate & 27 & $50.0 \%$ & 0 & $0.0 \%$ & 0 & $0.0 \%$ & \\
\hline & Good & 21 & $38.9 \%$ & 54 & $100.0 \%$ & 54 & $100.0 \%$ & \\
\hline
\end{tabular}

P: Friedman test

$* \mathrm{P}<0.05$ (Significant)

Table 3 and Figure 1: demonstrates the change at knowledge level during different phases of the study. It is clear that knowledge about reproductive health and adolescent, only $61 \%$ of the sample recorded high level which significantly improved to be among all sample subjects after intervention (100\% for both phases). Regarding knowledge about anatomy, physical and behavioral changes,48\%of the sample had good knowledge while after intervention all the subjects became knowledgeable and $92.6 \%$ after 3 month of intervention. As regard knowledge about menstruation and menstrual hygiene, $40.7 \%$ of the sample had good knowledge while after intervention all the subjects became knowledgeable and $96.3 \%$ after 3 month of intervention. Regarding knowledge about breast self-examination, only $22.2 \%$ of the sample recorded high level which significantly improved to be among all sample subjects after intervention (100\% for both phases). Concerning knowledge about premarital counseling, 35.2\% of the sample had good knowledge while after intervention $96.3 \%$ of the subjects became knowledgeable and $81.5 \%$ after 3 month of intervention. Regarding knowledge about sexual transmitted diseases, $44.4 \%$ of the sample recorded high level which significantly improved to be among all sample subjects after intervention (100\% for both phases). As regard knowledge about diet, $83.3 \%$ of the sample had good knowledge while after intervention all the subjects became knowledgeable and $88.9 \%$ after 3 month of intervention. Concerning knowledge about smoking and addiction, $22.2 \%$ of the sample had good knowledge while after intervention all the subjects became knowledgeable and $83.3 \%$ after 3 month of intervention. Regarding knowledge about role of health awareness teachers in relation to adolescent reproductive health, $70.4 \%$ of the sample recorded high level which significantly improved to be among all sample subjects after intervention ( $100 \%$ for both phases). 


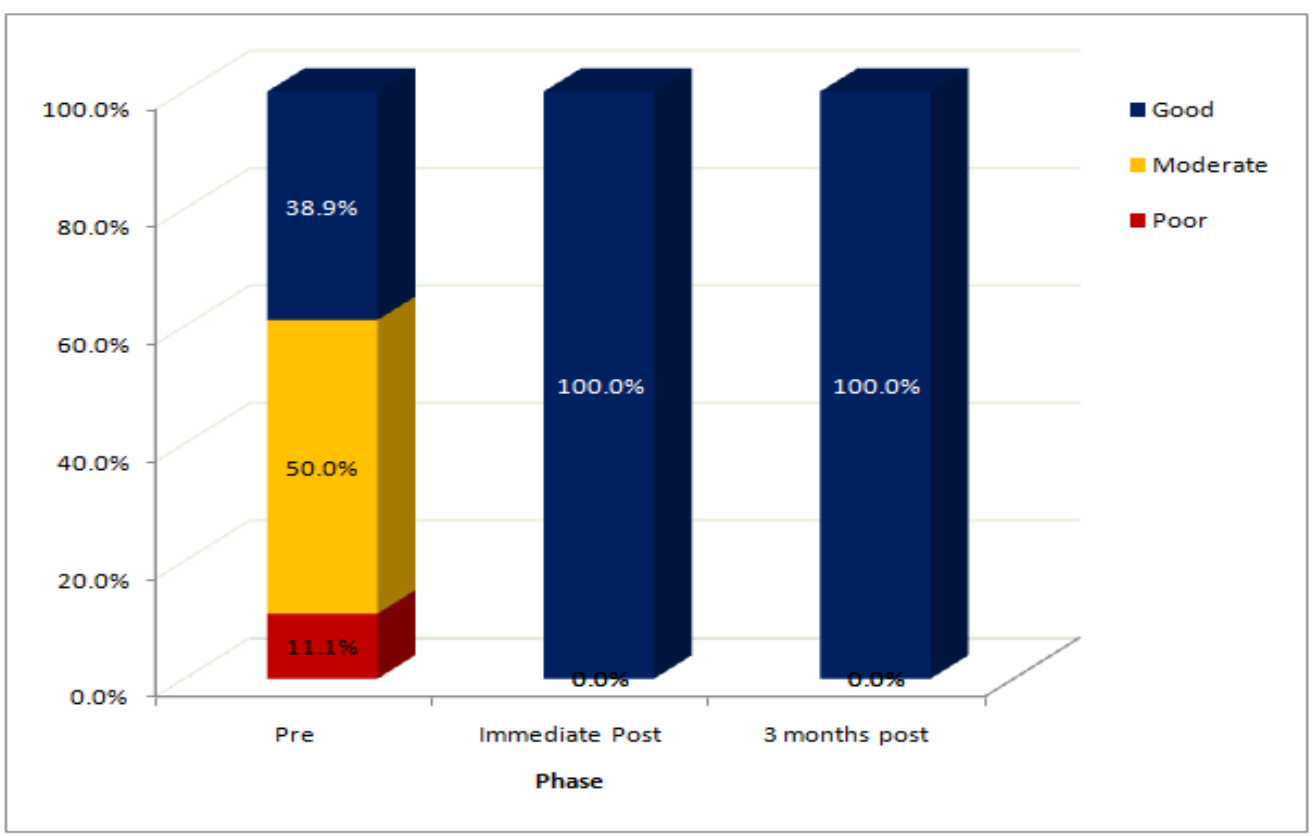

Figure1: Level of knowledge of health awareness teachers regarding adolescents' reproductive health during pre-program immediate post- program and 3 months post program

Table 4: Level of practice of the health awareness teachers to breast self-examination pre-program, immediately post-program and 3 months post-program

\begin{tabular}{|c|c|c|c|c|c|c|c|}
\hline \multirow[t]{3}{*}{ Breast self examination } & \multicolumn{6}{|c|}{ Phase } & \multirow[t]{3}{*}{$\mathbf{P}$} \\
\hline & \multicolumn{2}{|c|}{ Pre } & \multicolumn{2}{|c|}{ Immediate Post } & \multicolumn{2}{|c|}{3 months post } & \\
\hline & No & $\%$ & No & $\%$ & No & $\%$ & \\
\hline Poor & 49 & $90.7 \%$ & 0 & $0.0 \%$ & 8 & $14.8 \%$ & $0.001 *$ \\
\hline Moderate & 5 & $9.3 \%$ & 0 & $0.0 \%$ & 29 & $53.7 \%$ & \\
\hline Good & 0 & $0.0 \%$ & 54 & $100.0 \%$ & 17 & $31.5 \%$ & \\
\hline Range & \multicolumn{2}{|c|}{$0-8$} & \multicolumn{2}{|c|}{$9-16$} & \multicolumn{2}{|c|}{$3-15$} & \\
\hline Mean \pm SD & \multicolumn{2}{|c|}{$1.3 \pm 2.1$} & \multicolumn{2}{|c|}{$14.9 \pm 1.6$} & \multicolumn{2}{|c|}{$9.7 \pm 3.5$} & \\
\hline
\end{tabular}

P: Friedman test

$* \mathrm{P}<0.05$ (Significant)

Table 4 and figure 2: Shows the level of practice of health awareness teachers to breast self-examination (BSE) pre-program, immediately post-program and 3 months post-program. Regarding the breast selfexamination (BSE), none of the study sample had a good practice before intervention while all the sample became good practice immediately after intervention and reduced to $31.5 \%$ after 3 months post program. The difference was statistically significant $(\mathrm{P}<0.001)$.

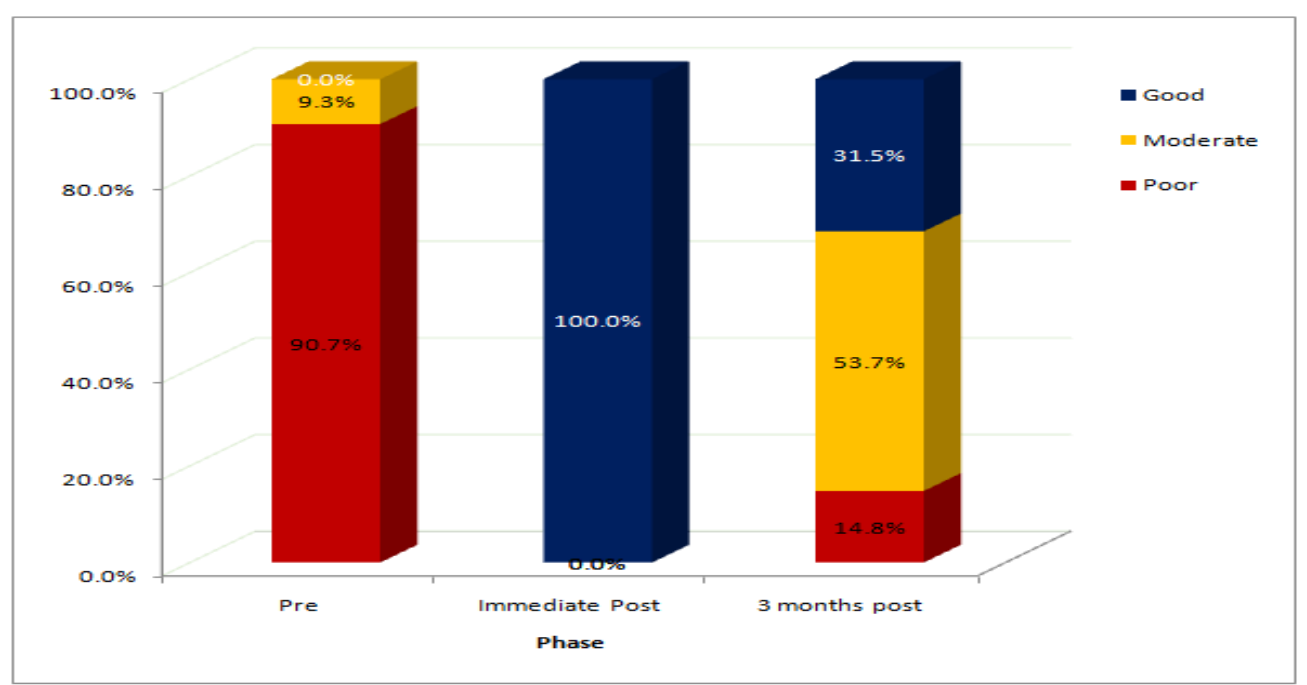

Figure 2: Level of practice of the health awareness teachers to breast self-examination pre-program, immediately post-program and 3 months post-program. 
Effect of Health Education Program on Improving Health Awareness Teachers Knowledge....

Table 5: Relationship between overall knowledge of the health awareness teachers regarding adolescents' reproductive health pre-program, and their socio-demographiccharacteristics

\begin{tabular}{|c|c|c|c|c|c|c|c|}
\hline \multirow[t]{3}{*}{ Demographic data } & \multicolumn{6}{|c|}{ Overall knowledge } & \multirow[t]{3}{*}{$M C P$} \\
\hline & \multicolumn{2}{|c|}{ Poor } & \multicolumn{2}{|c|}{ Moderate } & \multicolumn{2}{|c|}{ Good } & \\
\hline & No & $\%$ & No & $\%$ & No & $\%$ & \\
\hline \multicolumn{7}{|l|}{ Age in years } & \multirow[t]{4}{*}{0.511} \\
\hline . $25-<35$ & 4 & $20.0 \%$ & 10 & $50.0 \%$ & 6 & $30.0 \%$ & \\
\hline - $\quad 35-<45$ & 2 & $6.5 \%$ & 15 & $48.4 \%$ & 14 & $45.2 \%$ & \\
\hline - $45-53$ & 0 & $0.0 \%$ & 2 & $66.7 \%$ & 1 & $33.3 \%$ & \\
\hline \multicolumn{7}{|l|}{ Marital status } & \multirow[t]{4}{*}{0.513} \\
\hline - $\quad$ Married & 4 & $10.3 \%$ & 20 & $51.3 \%$ & 15 & $38.5 \%$ & \\
\hline - $\quad$ Single & 2 & $25.0 \%$ & 4 & $50.0 \%$ & 2 & $25.0 \%$ & \\
\hline - Divorced & 0 & $0.0 \%$ & 3 & $42.9 \%$ & 4 & $57.1 \%$ & \\
\hline \multicolumn{7}{|l|}{ Educational Level } & \multirow[t]{3}{*}{$0.013^{*}$} \\
\hline - $\quad$ Bachelor degree & 6 & $12.2 \%$ & 27 & $55.1 \%$ & 16 & $32.7 \%$ & \\
\hline - $\quad$ postgraduate studies (Diploma) & 0 & $0.0 \%$ & 0 & $0.0 \%$ & 5 & $100.0 \%$ & \\
\hline \multicolumn{7}{|l|}{ Experience in years } & \multirow[t]{3}{*}{0.712} \\
\hline - less than 3 years & 4 & $14.3 \%$ & 14 & $50.0 \%$ & 10 & $35.7 \%$ & \\
\hline - 3 years and more & 2 & $7.7 \%$ & 13 & $50.0 \%$ & 11 & $42.3 \%$ & \\
\hline \multicolumn{7}{|l|}{ Do you have adolescent in your family? } & \multirow[t]{3}{*}{0.449} \\
\hline - No & 3 & $14.3 \%$ & 12 & $57.1 \%$ & 6 & $28.6 \%$ & \\
\hline - $\quad$ Yes & 3 & $9.1 \%$ & 15 & $45.5 \%$ & 15 & $45.5 \%$ & \\
\hline \multicolumn{7}{|l|}{ Adolescents in family } & \multirow[t]{4}{*}{0.911} \\
\hline - One & 1 & $12.5 \%$ & 4 & $50.0 \%$ & 3 & $37.5 \%$ & \\
\hline $2-3$ & 2 & $10.0 \%$ & 9 & $45.0 \%$ & 9 & $45.0 \%$ & \\
\hline . $4+$ & 0 & $0.0 \%$ & 2 & $40.0 \%$ & 3 & $60.0 \%$ & \\
\hline \multicolumn{7}{|l|}{ Type of residence } & \multirow[t]{3}{*}{0.161} \\
\hline • $\quad$ Rural & 1 & $9.1 \%$ & 3 & $27.3 \%$ & 7 & $63.6 \%$ & \\
\hline - Urban & 5 & $11.6 \%$ & 24 & $55.8 \%$ & 14 & $32.6 \%$ & \\
\hline
\end{tabular}

MCP: Mont Carlo exact probability

$* \mathrm{P}<0.05$ (significant)

Table 5: shows relationship between overall knowledge of the health awareness teachers regarding adolescents' reproductive health pre-program, and their socio-demographic characteristics. It was observed that there are no any significant differences between health awareness teachers' knowledge and their socio-demographic characteristics except educational level. As regarding educational level, 32.7\% of those who had a Bachelor degree had a good knowledge compared to $100 \%$ of those who had postgraduate studies (Diploma) with significant difference $\mathrm{P}<0.013^{*}$

Table 6: Relationship between practice level of the health awareness teachers to breast self-examination and their socio-demographic characteristics

\begin{tabular}{|c|c|c|c|c|c|}
\hline \multirow[t]{3}{*}{ Demographic data } & \multicolumn{4}{|c|}{ Breast self examination } & \multirow[t]{3}{*}{$M C P$} \\
\hline & \multicolumn{2}{|c|}{ Poor } & \multicolumn{2}{|c|}{ Moderate } & \\
\hline & No & $\%$ & No & $\%$ & \\
\hline \multicolumn{5}{|l|}{ Age in years } & \multirow[t]{4}{*}{0.501} \\
\hline - $25-<35$ & 17 & $85.0 \%$ & 3 & $15.0 \%$ & \\
\hline $35-<45$ & 29 & $93.5 \%$ & 2 & $6.5 \%$ & \\
\hline . $45-53$ & 3 & $100.0 \%$ & 0 & $0.0 \%$ & \\
\hline \multicolumn{5}{|l|}{ Marital status } & \multirow[t]{4}{*}{0.650} \\
\hline - married & 35 & $89.7 \%$ & 4 & $10.3 \%$ & \\
\hline - $\quad$ single & 7 & $87.5 \%$ & 1 & $12.5 \%$ & \\
\hline - $\quad$ Divorced & 7 & $100.0 \%$ & 0 & $0.0 \%$ & \\
\hline \multicolumn{5}{|l|}{ Educational Level } & \multirow[t]{3}{*}{0.384} \\
\hline - $\quad$ Bachelor degree & 45 & $91.8 \%$ & 4 & $8.2 \%$ & \\
\hline - $\quad$ postgraduate studies (Diploma) & 4 & $80.0 \%$ & 1 & $20.0 \%$ & \\
\hline \multicolumn{5}{|l|}{ Experience in years } & \multirow[t]{3}{*}{0.135} \\
\hline - less than 3 years & 27 & $96.4 \%$ & 1 & $3.6 \%$ & \\
\hline - 3 years and more & 22 & $84.6 \%$ & 4 & $15.4 \%$ & \\
\hline \multicolumn{5}{|l|}{ Do you have adolescent in your family? } & \multirow[t]{3}{*}{0.363} \\
\hline - no & 20 & $95.2 \%$ & 1 & $4.8 \%$ & \\
\hline - yes & 29 & $87.9 \%$ & 4 & $12.1 \%$ & \\
\hline \multicolumn{5}{|l|}{ Adolescents in family } & \multirow[t]{4}{*}{0.655} \\
\hline - One & 7 & $87.5 \%$ & 1 & $12.5 \%$ & \\
\hline - $2-3$ & 17 & $85.0 \%$ & 3 & $15.0 \%$ & \\
\hline - $4+$ & 5 & $100.0 \%$ & 0 & $0.0 \%$ & \\
\hline \multicolumn{5}{|l|}{ Type of residence } & \multirow[t]{3}{*}{0.983} \\
\hline - $\quad$ Rural & 10 & $90.9 \%$ & 1 & $9.1 \%$ & \\
\hline - Urban & 39 & $90.7 \%$ & 4 & $9.3 \%$ & \\
\hline
\end{tabular}

MCP: Mont Carlo exact probability 
Table 6: Relationship between practice level of the health awareness teachers to breast self-examination and their socio-demographic characteristics. It was obvious that there are no anysignificant difference s between health awareness teachers' practice to breast self-examination and their socio-demographic characteristics.

Table 7: Correlation between heath awareness teachers' knowledge regarding adolescent reproductive health and breast self-examination practice

\begin{tabular}{|c|c|c|c|}
\hline \multirow[t]{2}{*}{ Phase } & \multirow[t]{2}{*}{ Knowledge } & \multicolumn{2}{|c|}{ Total score of breast self exam } \\
\hline & & $\mathbf{r}$ & $\mathbf{P}$ \\
\hline \multirow[t]{10}{*}{ Pre } & Knowledge about reproductive health and adolescent & -.16 & .241 \\
\hline & knowledge about anatomy and physical and behavioral changes & .14 & .308 \\
\hline & knowledge about menstruation and menstrual hygiene & .18 & .206 \\
\hline & knowledge about breast self-examination & .21 & .129 \\
\hline & knowledge about premarital counseling & .03 & .837 \\
\hline & knowledge o sexual transmitted diseases & .04 & .759 \\
\hline & knowledge about diet & -.04 & .790 \\
\hline & knowledge about smoking and addiction & -.02 & .879 \\
\hline & $\begin{array}{l}\text { knowledge about role of health awareness teachers in relation to adolescent } \\
\text { reproductive health }\end{array}$ & .17 & .223 \\
\hline & Overall knowledge & .09 & .532 \\
\hline \multirow{9}{*}{$\begin{array}{l}\text { Immediate } \\
\text { Post }\end{array}$} & Knowledge about reproductive health and adolescent & .09 & .514 \\
\hline & knowledge about anatomy and physical and behavioral changes & $.360^{* *}$ & .008 \\
\hline & knowledge about menstruation and menstrual hygiene & .14 & .320 \\
\hline & knowledge about breast self-examination & .25 & .069 \\
\hline & knowledge about premarital counseling & -.14 & .302 \\
\hline & knowledge o sexual transmitted diseases & $.351^{* *}$ & .009 \\
\hline & knowledge about diet & -.18 & .184 \\
\hline & knowledge about smoking and addiction & $.450^{* *}$ & .001 \\
\hline & $\begin{array}{l}\text { knowledge about role of health awareness teachers in relation to adolescent } \\
\text { reproductive health }\end{array}$ & $.333^{*}$ & .014 \\
\hline \multirow{10}{*}{$\begin{array}{l}3 \text { months } \\
\text { post }\end{array}$} & Overall knowledge & $.294^{*}$ & .031 \\
\hline & Knowledge about reproductive health and adolescent & .12 & .401 \\
\hline & knowledge about anatomy and physical and behavioral changes & .14 & .306 \\
\hline & knowledge about menstruation and menstrual hygiene & .23 & .091 \\
\hline & knowledge about breast self-examination & .15 & .274 \\
\hline & knowledge about premarital counseling & .01 & .950 \\
\hline & knowledge o sexual transmitted diseases & -.18 & .184 \\
\hline & knowledge about diet & .00 & .997 \\
\hline & knowledge about smoking and addiction & .11 & .425 \\
\hline & $\begin{array}{l}\text { knowledge about role of health awareness teachers in relation to adolescent } \\
\text { reproductive health }\end{array}$ & .20 & .154 \\
\hline
\end{tabular}

r: Pearson correlation coefficient $* \mathrm{P}<0.05$ (significant)

Table 7: Shows the correlation between heath awareness teachers' knowledge regarding adolescent reproductive health and breast self-examination practice. It is clear that before intervention there was no correlation between knowledge \& BSE. After applying the intervention program, knowledge about anatomy, physical and behavioral changes, knowledge about sexually transmitted diseases, knowledge about smoking and addiction and knowledge regarding role of health awareness teachers in relation to adolescent reproductive health rerecorded a significant moderate positive correlation with BSE. Three months after intervention, none of the knowledge domains recorded significant correlation with BSE.

\section{Discussion}

By far, this is a study on adolescent reproductive health conducted in KSA. It is the first study in Aljouf City and possible the country that has addressed health awareness teachers and their knowledge and practice regarding adolescent reproductive health.

The finding of the present study revealed the effectiveness of the health education program on improving health awareness teachers' knowledge regarding adolescent's reproductive health. The study results revealed that there was a statistically high significant improvement in knowledge level and scorein most assessed items of adolescent's reproductive healthamong health awareness teachers immediately post-program and 3 months post-program in comparison to that in pre-program. However, the improvement immediate postprogram was significant higher than three months post-program. This may be due to the effect of health educational program which helped health awareness teachers to gain knowledge. But three month after intervention the knowledge score slightly decreased. This is may be due to the health awareness teachers might forget some information and this is considered as normal event. A study conducted by Westwood (2006) to examine the reproductive health knowledge of school nurses, the results suggested that school nurses have 
insufficient knowledge ${ }^{14}$. Another study conducted by Gaheen et al (2011) revealed the effectiveness of the nursing intervention program on improving school nurses knowledge regarding adolescent reproductive health ${ }^{13}$.

The current study revealed that pre-program, the overall knowledge of health awareness teachers regarding breast self-examination (BSE) was insufficient and none of them were mentioned the steps of (BSE) pre-program, this could be due to the lack of information resources and health education programs about BSE. While immediately and 3 month after attending the health education program the result indicated that there was a significant increase in their knowledge regarding BSE, this could be due to the clarity, simple language and different methods and media used for teaching.In addition to the health awareness teachers' readiness to maintain a healthy life style was involved.A study conducted in India, the researchers assessed the impact of a health education intervention program about breast self- examination (BSE) among women in a semi-urban area in Madhya Prades, India, their study revealed a significant improvement in knowledge regarding all aspects of breast self- examination of the intervention group from pre- to post-test ${ }^{15}$.

Regarding thelevel of practice of breast self-examination(BSE), thefindings of the present study revealed none of the study sample had a good practice before intervention while all the sample became good practice immediately after intervention and reduced to $31.5 \%$ after 3 months post program. The difference was statistically significant. Theseresults may be due to lack of knowledge about BSE among health awareness teachers before the education intervention. These results supported by a study conducted by Seif\& Aziz (2000) they mentioned that women who had insufficient knowledge about BSE pre-education program were not practicing $\mathrm{it}^{16}$. Another study conducted in Turkey (2009) revealed that both video and model methods of education were effective in increasing teachers' knowledge and practice of $\mathrm{BSE}^{17}$.

The results of the present study found that there are no any significant differences between health awareness teachers' practice of breast self-examination and their socio-demographic characteristics. However, a study conducted by Gaheenet al (2011) mentioned that there is no any relationship between the practice of BSE immediately post-program and the school nurse's socio-demographic characteristics, but there is a positive relationship between the school nurses practice of BSE and their educational level in the 3 months postprogram $^{13}$. A study conducted by Borawski(2015) examine the effectiveness of health education teachers and school nurses teaching Sexually Transmitted Infections/Human Immunodeficiency Virus Prevention Knowledge and Skills in High School. The results of this study suggest that while classroom health education teachers may be skilled at imparting knowledge, they may be less effective with instruction involving skills ${ }^{18}$.

The findings of the current study also indicated that there are no any significant differences between health awareness teachers' knowledge about adolescents' reproductive health and their socio-demographic characteristics except educational level. Borawski et al. (2015) mentioned that some of information is provided to classroom health education teachers as part of the regular science and/or health education curricula ${ }^{18}$. Gaheen et al. study (2011) found relationship between the knowledge of school nurses regarding adolescent's reproductive health in the pre-program and the presence of adolescents in their families; this may be due to that the presence of adolescents in their family motivates the mothers to seek and understand about the adolescence period changes ${ }^{13}$.

\section{Conclusion and Recommendation}

It can be concluded from this study thathealth awareness teachersdid not havesufficient knowledge about adolescent's reproductive health pre-program. The implementation of the program was associated with high significant improvement in knowledge level and score among study subjects immediately post-program and 3 months post-program. However, the improvement immediately post program was significant higher than 3 months post-program. These results agree with the first hypothesis of the present study which stated that that educational program has a positive effect on the health awareness teachers' knowledge regarding adolescent's reproductive health.

It can also be concluded from this study that there is no significant effect of socio-demographic characteristics on health awareness teachers' level of knowledge. This finding did not support our second hypothesis which stated that socio-demographic characteristics of health awareness teachers will have an effect on their level of knowledge regarding adolescent's reproductive health. However, the educational level has effect the health awareness teachers'level of knowledge regarding adolescent's reproductivehealth.

The present study found that there is an improvement in the level of health awareness teachers' performanceof breast self-examination technique (BSE) immediately after the educational program, this agreed with the first hypothesis of the present study. It can also conclude from this study that there is no significant effect of socio-demographic characteristics of health awareness teachers on their practice of BSE, this finding did not support our second hypothesis.

\section{Recommendations:}


1- Raising the awareness of health awareness teachers about adolescent's reproductive health through the periodic health education programsthathelp them to offer high quality of care to adolescents in a nonjudgmental confidential mannerand to know where to refer adolescents for more information and health services.

2- Educational materials on adolescent's reproductive health (posters, booklets and models) should be available in school area to facilitate the information provided to health awareness teachers to help health awareness teachers to disseminate this information to adolescence.

3- Physicians and nurses play a significant role at the school area,so educational program should be done by them to provide adequate information to health awareness teachers regarding adolescent's reproductive health topics using suitable educational materials.

4- School nurse as health care providers should be available at the school area. In addition to develop high school nursing curricula that give school nurses appropriate information about adolescent's reproductive health.

5- Research with large sample is needed to identify the health awareness teachers' level of knowledge and practice regarding adolescent's reproductive health.

\section{Acknowledgments}

The researchers would like to thank the Agency of Scientific Research and post-graduate Studies Aljouf University- Kingdom of Saudi Arabia- for supporting and funding this research project number 35/316. This study would not have been possible without the efforts and hard work of many individuals. We would like to thank the health awareness teachers for their participation and time and the supporting of the Dean of the college of Applied Medical Sciences.

\section{References}

[1] Naeem, Z. (2013).Medical and Behavioral Problems among Saudi Adolescents. Int J Health Sci (Qassim). 2013 Jun; 7(2): V-VI.

[2] UNICEF.(2011). The state of the world's children: Adolescence an age of opportunity. United Nations Children Fund (UNICEF). February 2011.

[3] US Census Bureau.Internationalprograms.International data base. (2014) Available at:

http://www.census.gov/population/international/data/idb/region.php?N=\%20Results\%20\&T=10\&A=separate \&RT=0\&Y=2014\&R=$1 \& \mathrm{C}=$ SA Accessed April 11, 2014

[4] AlBuhairan, F., \& Olsson. T. (2014).Advancing adolescent health and health services in Saudi Arabia: Exploring healthcare providers' needs, attitudes andknowledge.Adv Med EducPract, 5, pp. 281-287

[5] Obermeyer, C., \&Bott, S. Sassine, A. (2015).Arab adolescents: Health, gender, and social context. J Adolesc Health, 57, pp. 252262

[6] Khnna, J.,\&Graffin D. (2009). Reproductive health overview and lessons: Key to brighter future. Bienniel report.1-20. World Health Organization (WHO) Geneva.

[7] World Health Organization (WHO)(2009). Definition of reproductive health.(2009). World Health Organization (WHO), Geneva.

[8] World Health Organization (WHO) (2001).Orientation program on adolescent's health for health care providers. The challengeof developing effective programs. Geneva: WHO, 2001; 1-1.

[9] Majer, L., \&Coyle, K. (2007).Adolescents reproductive health: roles for school personnel in prevention and early intervention.Journal of school health. 24 (9): 104-113.

[10] Helal, H.,\&Al Hudaifi,D. (2015). Role of the School Nurse as perceived by school children' Parent in Jeddah. I nternational Journal for Innovation Education and Research.Vol:-3 No-11.

[11] Schainker, E., Brien M., Fox, D., \&Bauchner, H. (2005). School nursing services: use in an urban public school system. Article of Pediatrics and Adolescents Med, 159(1):83-87.

[12] Lamada, S. (2004). Knowledge, attitude and practices ofadolescent' female regarding reproductive health. Doctoral thesis submitted to the facuty of Nursing, Alexandria University.

[13] Gaheen, M., Fahmy, N., Rakha, S., \&Elsabagh, N. Effect of Nursing Intervention on the Knowledge and Performance of School toward Adolescent's Reproductive Health in Tanta City. Egyptian Journal of Health Care, Faculty of Nursing, AinShamesUniversity, June 2011, Vol 2 No 1.

[14] Westwood,J.,\&Mullan, B. (2006).Knowledge of school nurses in the U.K. regarding sexual health education. Journal of School Nursing. 22 (6): 352-357.

[15] Gupta, S.(2009). Impact of a health education intervention program regarding breast self examination by women in a semi-urban area of Madhya Pradesh, India.Asian Pac J Cancer Prev. 10(6):1113-7.

[16] Seif, F.,\& Aziz, M. (2000). Effect of breast self examination (BSE) program on knowledge, attitude \& practice of group of working women.Ain Shams Faculty of Nursing. Journal of the Egyptian Nat. Cancer Inst., 12, (2), June: 105-11.

[17] Avci, IA., \&Gozum, S.(2009). Comparison of two different educational methods on teachers' knowledge, beliefs and behaviors regarding breast cancer screening.Eur J OncolNurs. Apr;13(2):94-101.

[18] Borawski, E., Tufts, K., Trapl, E., Yoder, L. \&Lovegreen, L (2015).Effectiveness of Health Education Teachers and School Nurses Teaching Sexually Transmitted Infections/Human Immunodeficiency Virus Prevention Knowledge and Skills in High School.JSch Health. 2015 Mar; 85(3): 189-196. 